\title{
The isolation and cloning of chromosomal DNA specific for a clonal population of Staphylococcus aureus by subtractive hybridisation
}

\author{
W. A. EL-ADHAMI, P. R. STEWART and K. I. MATTHAEI* \\ Division of Biochemistry and Molecular Biology, Faculty of Science and * Division of Biochemistry and \\ Molecular Biology, John Curtin School of Medical Research, Australian National University, Canberra ACT \\ 0200, Australia
}

\begin{abstract}
Subtractive hybridisation was used to screen for and identify conserved DNA sequences associated with clinical, clonal populations of Staphylococcus aureus. DNA from $S$. aureus strain ISP8 (a clinical isolate) was digested with TaqI and hybridised with randomly fragmented pooled DNA from 10 non-clinical (community) isolates of $S$. aureus. The mixture of DNA fragments was then ligated to AccI-digested and dephosphorylated pTZ19U. One recombinant plasmid (pWASA) was identified as containing specific DNA from strain ISP8; DNA sequencing revealed a 40-bp TaqI DNA fragment (WASA). PCR amplification and hybridisation analysis, with pWASA as a probe, showed that $84 \%$ of clinical isolates from a clonal line present in hospitals in major eastern Australian cities carried sequences homologous to WASA, compared with only $10 \%$ of community isolates. The isolates that hybridised were closely related by RFLP analysis to strain ISP8. The plasmid pWASA was used to identify, isolate and clone a 3.5-kb DraI fragment (DSA) from strain ISP8 total DNA. Sequence analysis of the DSA fragment identified two open reading frames (ORFs) of 2475 and $576 \mathrm{bp}$, respectively; the larger ORF1 contained a series of six tandem repeats, each consisting of 384 nucleotides. The nucleotide sequence of the repeats was $96 \%$ identical, and no significant sequence homologies to previously described protein sequences were identified. However, tandem repeats of amino acids are structural motifs characteristic of a number of gram-positive surface proteins, and are thought to play a role in generating genetic and phenotypic diversity in these and other bacteria.
\end{abstract}

\section{Introduction}

The ability of a bacterial pathogen to colonise a host, invade tissue, and cause disease is the result of a complex interaction of bacterial, host and environmental factors. However, not all strains of a pathogenic bacterial species are equally virulent, and many disease syndromes are caused by bacterial strains that belong to a few clones [1-4]. Restriction fragment length polymorphism (RFLP) analysis of community isolates and of methicillin-sensitive clinical isolates of Staphylococcus aureus (MSSA) showed that these two groups were not closely related, with a few exceptions, to each

Received 11 Feb. 1997; revised version accepted 22 April 1997.

Corresponding author: Dr W. A. El-Adhami. Present address: School of Biomedical Sciences, Curtin University of Technology, GPO Box U 1987, Perth, Western Australia 6001, Australia. other, nor to the multi-resistant (MRSA) types [5]. This absence of clonality in the MSSA and community isolates, despite their well conserved genomic organisation [5], suggests that strains with the greatest clinical impact arise from single or a few progenitors, which are or become singularly well-adapted as pathogens. These then become dominant through selection and are evident as closely related (clonal) lines. This raises questions as to whether successful pathogenic clones are equipped with particular combinations or arrangements of genes that are strongly selected through interaction with the vulnerable host and the clinical environment, and proliferate on that host or in that environment. Thus, an important question is raised: is it possible to predict virulence on the basis of the presence and arrangements of genes or DNA sequences in different staphylococcal lineages, i.e., on purely genetic evidence, without making assumptions about the production of particular enzymes or proteins by individual staphylococcal isolates or clones? If this is the case for $S$. aureus, then such 
predictor genes or sequences might be identified by selective molecular cloning techniques.

This report describes experiments that identify the presence of conserved DNA sequences, characteristic of clonal, clinical $S$. aureus strains, which are absent from non-clonal community strains, i.e., DNA sequences that are potential virulence determinants. This has been done by subtractive hybridisation and cloning of specific DNA sequences by methods used previously for identifying DNA sequences specific for the mouse Y-chromosome [6]. A similar approach has also been applied previously to cloning DNA sequences present in one cell population but not in another [7-10].

\section{Materials and methods}

\section{Bacterial strains and antibiotic susceptibilities}

S. aureus strain 8325-4 (ISP8) [11] was kindly provided by Dr P. Pattee, Iowa State University. The standard reference NCTC strain 8325 (parent of ISP8) was isolated originally in England in the 1950s from a clinical environment [12] and is similar to recent types of MRSAs and some recent MSSAs isolated in Australia [5]. Strain ANS46 is a multi-resistant $S$. aureus (MRSA), studied extensively in this and other laboratories, and is a representative of a clonal group referred to as type 46 (and subtypes within) that was dominant in major hospitals in the eastern Australian states during the period 1982-1986 [5, 8, 13-19]. MRSA strain Ib is representative of a group referred to as type I (subtype b), while type II isolate represents the type II group of MRSA prevalent in Canberra hospitals during the period 1989-1990 [5, 17, 19]. Strains SK565 and SK597 are from a collection of MRSA isolates [20] kindly provided by Professor R. A. Skurray, University of Sydney. These MRSA isolates were hospital-acquired and were isolated from patients with systemic infections during outbreaks of MRSA infection.

Clinical MSSA isolates were isolated from patients with minor staphylococcal infections admitted to Woden Valley Hospital, Canberra in 1993; these isolates were resistant to three or fewer antibiotics of the nine commonly tested for this organism and were not involved in infection outbreaks. Community $S$. aureus isolates were collected by nasal swabbing from a random selection of healthy university students with no history of hospitalisation, staphylococcal infection or disease, or antibiotic use, in Canberra during 1990; these isolates were, in general, resistant to not more than one antibiotic. Isolates were identified as $S$. aureus by growth and mannitol fermentation on $\mathrm{NaCl}$ $5 \% \mathrm{w} / \mathrm{v}$ Nutrient Agar (Oxoid) and by a positive coagulase test. Antibiotic susceptibilities were tested with the BBL Sensi-Disc System (Becton Dickinson) by measuring and comparing zones of inhibition of growth around antibiotic impregnated disks with those for standard resistant and sensitive strains, as described by the manufacturer.

\section{DNA preparation}

Growth and preparation of cells for total cellular DNA preparation was as described previously [8]. DNA in agarose plugs was prepared as described by Inglis et al. [16] and Stewart et al. [21]. Plasmid DNA from Escherichia coli was prepared by the alkaline lysis method [22], with the addition of a digestion step with lysozyme $4 \mathrm{mg} / \mathrm{ml}$ for $10 \mathrm{~min}$ at room temperature.

\section{Electrophoresis}

Clamped homogeneous electric field (CHEF DRII; BioRad, CA, USA) gel electrophoresis was in agarose $1 \% \mathrm{w} / \mathrm{v}$ gels at $200 \mathrm{~V}$ for a total of $26 \mathrm{~h}$ at $12-14^{\circ} \mathrm{C}$ in Tris-borate buffer $(45 \mathrm{mM}$ Tris, $45 \mathrm{mM}$ boric acid, $1 \mathrm{mM}$ EDTA, pH 8.3) with the following pulse parameters: first set, $23 \mathrm{~s}$ for $4 \mathrm{~h}$; second set, ramped with initial forward time of $1 \mathrm{~s}$ and final forward time of $40 \mathrm{~s}$ for $22 \mathrm{~h}$ [5, 21]. After electrophoresis, gels were stained with ethidium bromide $0.5 \mathrm{mg} / \mathrm{L}$, destained in water and photographed over a UV transilluminator. Characterisation and classification of the isolates into types or groups was on the basis of RFLP analysis and estimates of genetic distances [5].

Experimental strategy for construction of an ISP8 difference DNA library by subtractive hybridisation

The strategy applied was to hybridise total DNA from two sources: first, endonuclease-digested total DNA from a representative strain of the clinical population, putatively containing DNA of gene(s) associated specifically with the clinical population; and second, pooled and sheared total DNA from community (nonclinical) isolates. The latter shares most of the sequences found in the clinical isolate, except for the putative specific gene(s). By using an excess of community DNA to drive the hybridisation to completion, and so block the cloning of DNA sequences common to both the clinical and community DNA, the cloning of DNA sequences associated specifically with the clinical isolate may be achieved.

S. aureus NCTC strain 8325-4 (ISP8) was used as the standard strain representative of the clinical population; detailed genetic information is available for this strain [23]. ISP8 is related to the recent clinical types identified in major hospitals on the eastern Australian coast [5], but does not carry any of the known repeat sequences - such as IS elements, tranposons, plasmids, or bacteriophages - identified previously in staphylococci $[23,24]$ (P. Pattee, personal communication). 
Thus, ISP8 DNA $(20 \mu \mathrm{g})$ was digested for $17 \mathrm{~h}$ with restriction endonuclease TaqI (50 U) (Pharmacia). Total cellular DNA from 10 community $S$. aureus isolates was pooled, sheared, denatured and fragmented as described by Matthews et al. [8]. Sheared DNA from community $S$. aureus isolates was then mixed with Taq I-digested ISP8 DNA at a mass ratio of $200: 1$, boiled at $100^{\circ} \mathrm{C}$ for $10 \mathrm{~min}$, and then allowed to anneal at $65^{\circ} \mathrm{C}$ for $c .18 \mathrm{~h}$.

\section{Cloning of difference DNA}

A $0.5-\mu$ g sample of the annealed DNA mix (i.e., Taq Idigested ISP8 DNA and sheared DNA from community $S$. aureus isolates) was mixed with Acc I (Pharmacia)digested, dephosphorylated plasmid pTZ19U DNA (BioRad) at a mass ratio of 10:1 in the presence of T4 DNA ligase (Pharmacia) at $10 \mathrm{U} / 50 \mu \mathrm{l}$ of ligation buffer. The ligation reaction was performed at $16^{\circ} \mathrm{C}$ for $17 \mathrm{~h}$. A sample of the ligation mix was used to transform electrocompetent $E$. coli strain MC1061.1 (a rec $\mathrm{A}^{-}$derivative of strain $\mathrm{MC1061}$ obtained from $\mathrm{Dr}$ C. Rice, Washington University Medical School, St Louis, MO, USA). Transformed bacteria were grown on ampicillin-containing $(50 \mu \mathrm{g} / \mathrm{ml})$ Luria Agar medium [22].

\section{Screening transformants for ISP8 DNA}

Transformed bacteria were identified by growth on ampicillin-containing $(50 \mu \mathrm{g} / \mathrm{ml})$ Luria agar medium, and were screened for recombinant plasmids as follows. Sterile toothpicks were used to pick wellisolated colonies from the plates of transformed cells and were dipped into $25 \mu \mathrm{l}$ of freshly prepared cracking solution $(50 \mathrm{mM} \mathrm{NaOH}$, SDS $0.5 \% \mathrm{w} / \mathrm{v}$, $5 \mathrm{mM}$ EDTA, glycerol $10 \% \mathrm{v} / \mathrm{v}$, bromocresol green $0.01 \% \mathrm{w} / \mathrm{v}$ ), twirled quickly, then discarded. The samples were then heated at $68^{\circ} \mathrm{C}$ for $30 \mathrm{~min}$, cooled to room temperature, loaded on to an agarose $1 \% \mathrm{w} / \mathrm{v}$ gel, and electrophoresed (K. C. Reed, personal communication).

For pWASA, recombinant plasmids were identified by Southern transfer and hybridisation to total DNA probes from ISP8 and from community isolates (see below).

For pDSA, the polymerase chain reaction (PCR) was also used to screen pools of transformed clones to identify those with specific staphylococcal sequences. Briefly, pools of 10 transformed colonies were suspended in $0.5 \mathrm{ml}$ of sterile distilled water and boiled at $100^{\circ} \mathrm{C}$ for $10 \mathrm{~min}$. A $5-\mu 1$ volume was used in a PCR to amplify the specific target sequences with WSA $3^{\prime}$ and WSA $2 \mathrm{R}$ primers (Table 1) designed from sequence information obtained from genomic sequencing (see Results). Each PCR reaction mix (20 $\mu 1$ total volume) consisted of $10 \mathrm{mM}$ Tris- $\mathrm{HCl}, \mathrm{pH}$
9.0, $50 \mathrm{mM} \mathrm{KCl}, 1.5 \mathrm{mM} \mathrm{MgCl}_{2}$, gelatin $0.01 \% \mathrm{w} / \mathrm{v}$, Triton X-100 0.1\% v/v, $0.2 \mathrm{mM}$ dNTP (each), $5 \mathrm{pmol}$ primers (each), and $0.2 \mathrm{U}$ Super Taq DNA polymerase (PH Stehelin and CIE AG, Basel, Switzerland). PCR conditions with a FTS 4000 Thermal Sequencer (Corbett Research, Sydney, Australia) were as follows: $3 \mathrm{~min}$ at $94^{\circ} \mathrm{C} ; 35$ cycles of $10 \mathrm{~s}$ at $94^{\circ} \mathrm{C}, 10 \mathrm{~s}$ at $60^{\circ} \mathrm{C}$ and $20 \mathrm{~s}$ at $72^{\circ} \mathrm{C} ; 3 \mathrm{~min}$ at $72{ }^{\circ} \mathrm{C}$; and $5 \mathrm{~min}$ at $30^{\circ} \mathrm{C}$. Amplification products from different pooled samples (colonies) were electrophoresed [22], and stained. Where a particular pool produced a product, a second round of PCR amplification was performed on each of the constituent colonies in the pool to identify the clone with the target sequence.

\section{Southern transfer and hybridisation}

Recombinant plasmids and fragments of HindIII or SmaI-digested DNA were resolved by agarose gel electrophoresis (CHEF for SmaI fragments) [17, 21], transferred to membranes (Hybond $\mathrm{N}^{+}$; Amersham International), and hybridised to radioactively-labelled DNA probes by the method of Reed [25]. Radiolabelled DNA probes were prepared by random-priming $[26,27]$ with the Megaprime DNA Labelling System (Amersham) from: (i) total chromosomal DNA from strain ISP8; (ii) community isolates; and (iii) recombinant plasmids carrying ISP8-specific DNA.

\section{Sequencing of $3.5 \mathrm{~kb}$ Dral cloned DNA fragment}

The Erase-a-Base system (Promega) was used to generate a series of unidirectional deletions, in both directions, from the recombinant 3.5-kb DraI fragment. The double-stranded DNA from all deletion products was sequenced on an ABI (Applied Biosystems) model $373 \mathrm{~A}$ version 1.2.1 system at the Biomolecular Resources Facility (JCSMR, ANU, Canberra, Australia) with the universal primers $-21 \mathrm{M} 13$ and OT7, and the Taq DyeDeoxy Terminator Cycle Sequencing Kit (Prism; Applied Biosystems).

\section{Results}

\section{Antibiotic susceptibilities}

Strains ANS46, type Ib, type II, SK565 and SK597 were resistant to penicillin, methicillin, tetracycline, chloramphenicol, gentamicin, erythromycin and kanamycin. Strain ISP8 was susceptible to all seven antibiotics. Clinical MSSA isolates expressed resistance to three or fewer antibiotics (penicillin, tetracycline and erythromycin). Other than penicillin, the community isolates were susceptible to all antibiotics tested, except one isolate that was also resistant to erythromycin and tetracycline, and one isolate that was resistant also to erythromycin. 


\section{Isolation of E. coli transformants containing ISP8-specific DNA}

Recombinant plasmid DNA was prepared from $12 \mathrm{E}$. coli transformants and examined for specific ISP8 DNA by hybridisation to DNA probes generated from ISP8 total DNA, and from the pooled total DNA from community isolates. One recombinant plasmid (pWASA) that hybridised only to the total ISP8 DNA probe was identified (Fig. 1, lane 4). DNA sequencing revealed that it carried a 40-bp Taq I fragment. The sequence of this $T a q I$ fragment yielded no significant matches in the GenBank database (NCBI, NIH, USA).

To determine the distribution and the association of specific ISP8 DNA with different $S$. aureus isolates, pWASA was used to probe HindIII fragments from 20 clinical isolates (including MRSA and MSSA) and 20 community isolates (different from the isolates used in the initial subtractive hybridisation process). pWASA hybridised, under stringent conditions, to a corresponding fragment in $12(60 \%)$ of 20 clinical isolates and three $(10 \%)$ of 30 community isolates (Fig. 2). The isolates that hybridised belonged to a group of genetically closely related types (i.e., members of a clonal population) as defined by RFLP analysis [5, 17, 19]. The MRSA RFLP types were identified as type 46 , type Ib and type II [5, 17, 19], while the MSSA isolates ( $\mathrm{S} 5$ and $\mathrm{S} 6$ ) and community isolates (Co9, Co19 and Co32) had RFLP types closely related to that of ISP8 (Fig. 3). The MSSA isolate S174 was

a

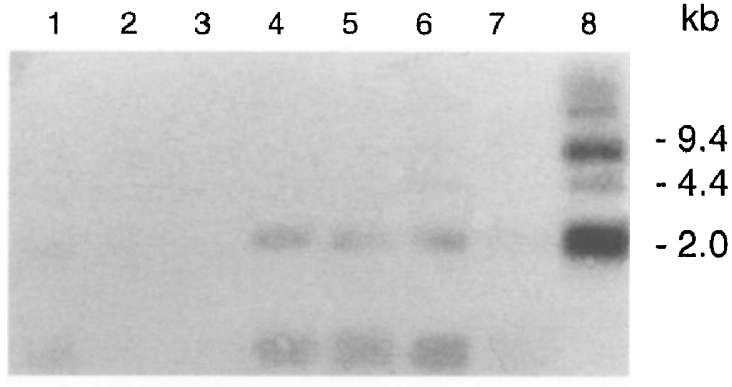

b

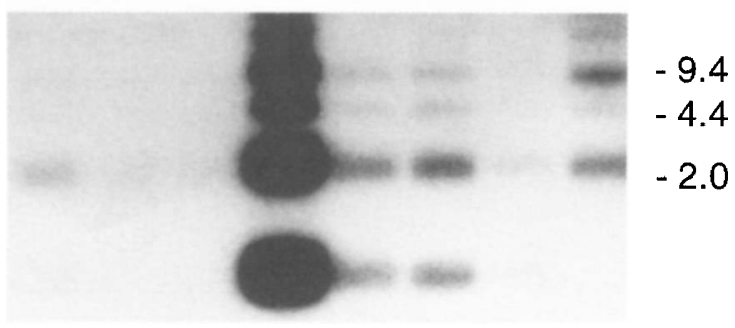

Fig. 1. Detection of recombinant plasmids containing ISP8-specific DNA. Plamid recombinants (lanes 2-8) were hybridised with: $\mathbf{A}$, radiolabelled pooled total community DNA; B, radiolabelled total ISP8 DNA. Lane 1 contains pTZ19U DNA. Hybridisation signals seen in lanes other than lanes 4 and 8 are caused by non-specific binding of DNA probes to plasmid DNA, and to slight variation in plasmid DNA loading. Molecular sizes were determined by comparison with $\lambda$ phage DNA digested with HindIII. identified as closely related to the MRSA types, but differed by the absence of the mec region, which is a $40-\mathrm{kb}$ segment carrying resistance genes $[19,28]$.

\section{RFLP analysis and map position of the specific sequence}

Selected $S$. aureus isolates representing major MRSA types identified in Australian hospitals during the last decade [5, 17, 19], MSSA isolates and community isolates carrying the 40-bp WASA sequence were examined for SmaI polymorphisms and the genomic map position of the identified sequence. All isolates showed a SmaI fragment of near identical size that hybridised with pWASA; an example is shown in Fig. 3. The physical map location of this fragment was found to be identical in the genomes of representative isolates from the closely related RFLP types [5].

\section{Sequencing of DraI-digested genomic DNA}

Primers WSA $5^{\prime}$ and WSA $3^{\prime}\left(24\right.$ mers in $5^{\prime}$ and $3^{\prime}$ directions; Table 1) were designed from the 40-bp sequence (WASA) and were used to obtain more sequence information by cycle sequencing with a Taq DyeDeoxy Terminator kit (see Materials and methods). The DNA used in this reaction was gel-purified Dra Idigested ISP8 genomic DNA within the $2-4 \mathrm{~kb}$ region identified as containing a $3.5-\mathrm{kb}$ fragment carrying WASA. Cycle sequencing was successful with primer WSA $3^{\prime}$, and c. 300 bp of DNA sequence was obtained in one direction. Another primer (WSA 2; Table 1) was designed from the 300-bp sequence and was used to extend, in the same direction as in WSA $3^{\prime}$, the DNA sequence information by cycle sequencing. An extra 229 bp of sequence was obtained with primer WSA 2, and thus a total of $529 \mathrm{bp}$ of sequence in this direction was compiled. Although the same DNA template was used with both the WSA 5' and WSA 3' primers, no sequence information was obtained with the former. This might be explained by the nature of the nucleotide sequence of the DNA template in that particular direction, i.e., rich in A and $T$ nucleotides, or by the presence of repeat sequences similar to the WSA 5 ' sequence, causing annealing of the primer at multiple sites.

Analysis of the 529-bp sequence revealed multiple open reading frames (ORFs) with no significant similarities to either DNA or (after translation) to amino-acid sequences deposited in the GenBank database. The primers used to screen transformants for ISP8 DNA, i.e., for pDSA, as described in the following section, were designed from WASA and from the compiled 529-bp sequence information.

\section{Isolation of a DraI fragment from ISP8 carrying WASA}

pWASA hybridised to a $c .3 .5-\mathrm{kb}$ Dra I fragment, a 13kb $A c c$ I fragment, a 10-kb XbaI fragment, a 3.6-kb 
a
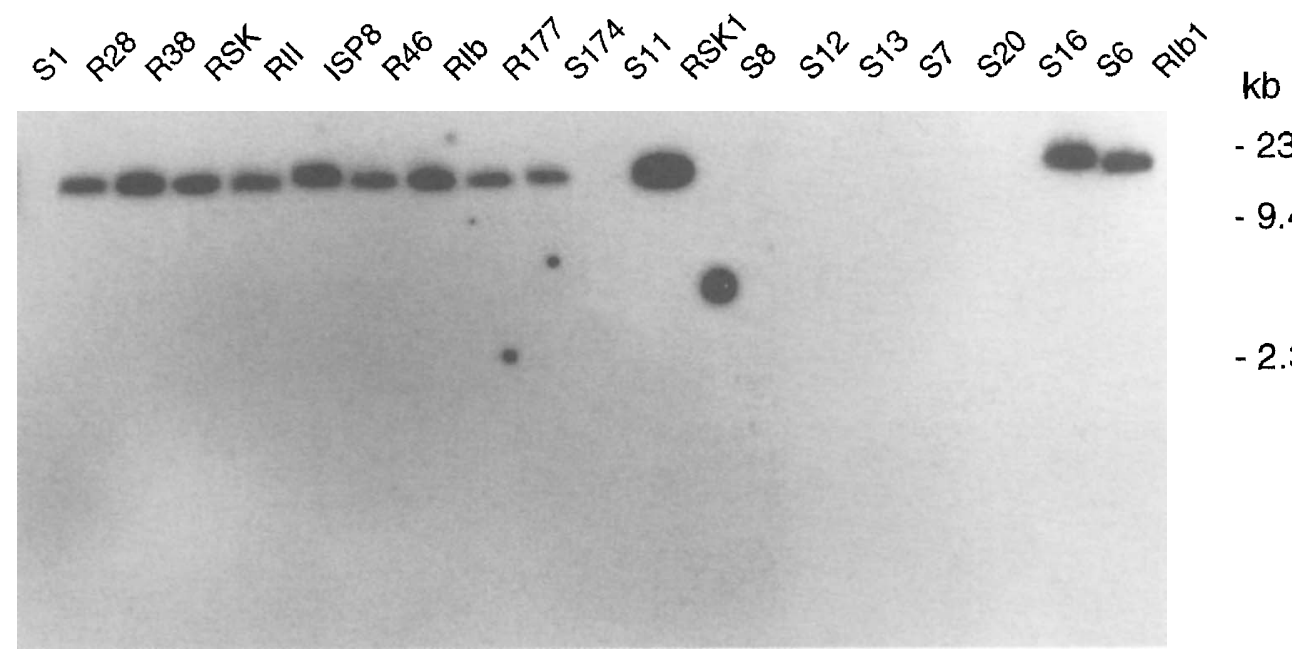

b
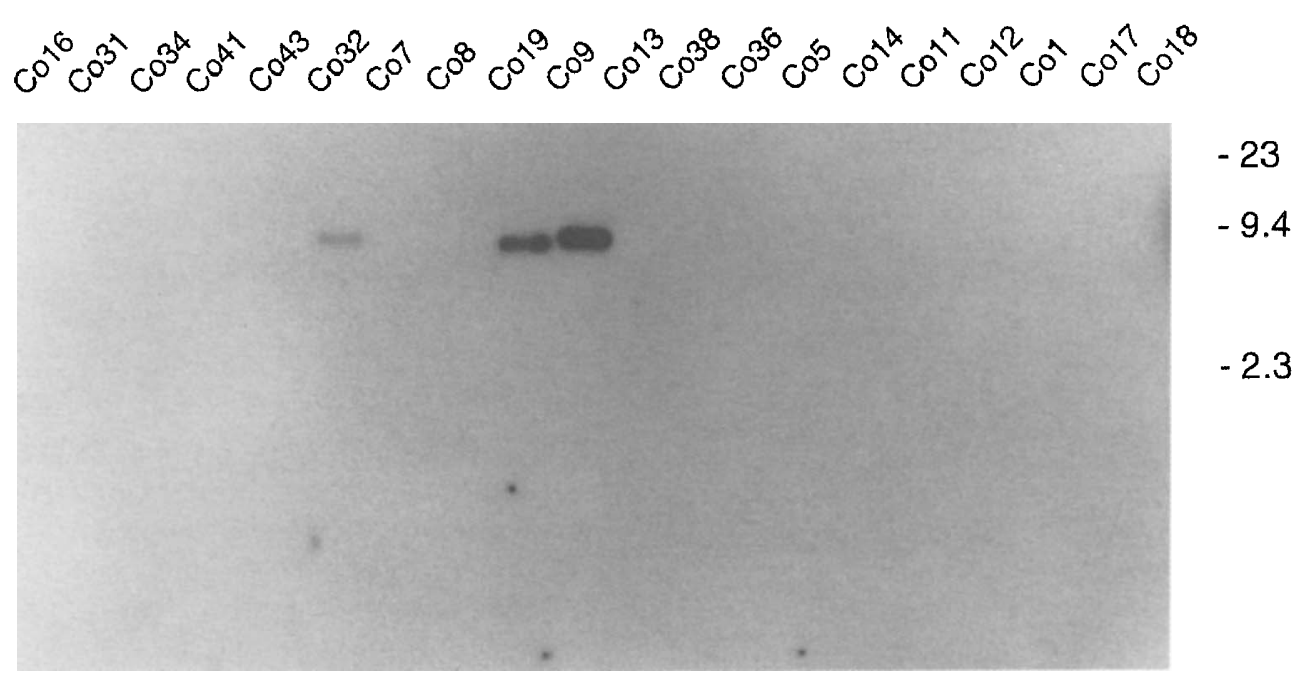

Fig. 2. Detection and distribution of WASA-homologous sequences among: A, clinical; B, community $S$. aureus isolates following hybridisation of HindIII-digested total DNA from the isolates with radiolabelled pWASA DNA. Co, community isolates; S, clinical methicillin-susceptible (MSSA) isolates; R, clinical methicillin-resistant (MRSA) isolates; R46, ANS46; RSK, SK565; RSK1, SK597; RIb and RIb1, representatives of type I (b) MRSAs; RII, representative of type II MRSAs (see text). Signal intensity difference is caused by variation in DNA loading. Molecular sizes were determined by comparison with $\lambda$ phage DNA digested with HindIII.

$A l u \mathrm{I}$ fragment and a $19-\mathrm{kb}$ Pst I fragment from digested ISP8 DNA. DraI was used to generate a genomic library from fragments of $2-4 \mathrm{~kb}$ in size following ligation into HincII-digested and dephosphorylated pTZ19U. The recombinant library was screened for positive clones by PCR. A recombinant plasmid (pDSA; Fig. 4, lane 12b) carrying a DraI fragment of $3.5 \mathrm{~kb}$ that contained WASA sequences was isolated and sequenced.

PCR amplification as a diagnostic tool to identify closely related $S$. aureus isolates

A group of 81 isolates consisting of clinical MRSA, clinical MSSA and community $S$. aureus isolates (including those tested above) was examined for specific DNA sequences by PCR amplification with the same primers used for isolation of the DraI fragment. All $40 \mathrm{MRSA}$ isolates yielded the expected fragment of c. $300 \mathrm{bp}$, whereas only three of 11 MSSA and three of 30 community isolates contained the same size fragment (data not shown). These six MSSA and community isolates, although susceptible, were found to be closely related (same clonal population) to the resistant types [5]. These results suggest that the sequence is specific to a closely related population of $S$. aureus, particularly the clinical MRSA isolates, which have been collected over the last decade from hospitals in different geographical locations in eastern Australia. It is noteworthy that three of the MRSA isolates were isolated from hospitals in the USA.

\section{Features of the DSA sequence}

The sequenced DSA fragment was examined for ORFs in the six possible frames with MacVector 3.5 software 
S13 Co9 Co19 RSK1 ISP8 Co32 S5 S6 R28 R29

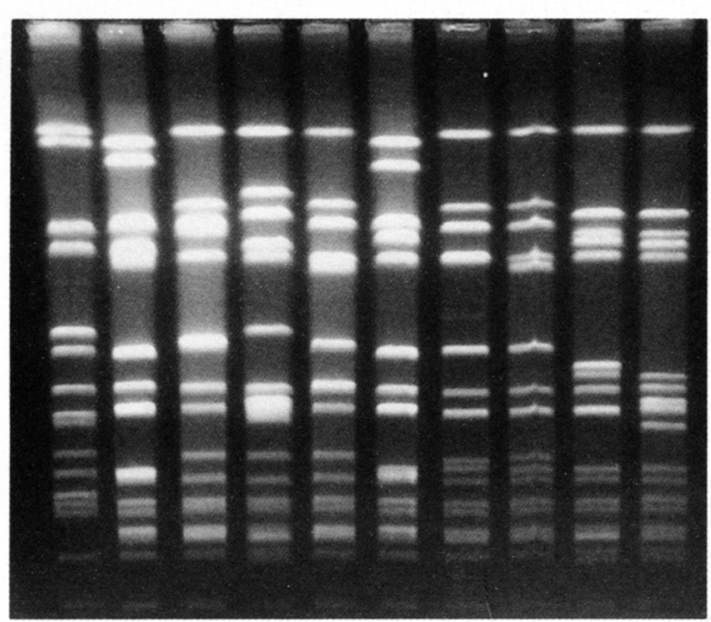
$\begin{array}{lllllllll}\text { S13 } & \text { Co9 } & \text { Co19 } & \text { RSK1 } 1 \text { ISP8 } & \text { Co32 } & \text { S5 } & \text { S6 } & \text { R28 } & \text { R29 }\end{array}$

Fig. 3. RFLP and mapping analysis of WASA sequences. A. Clamped homogeneous electric field (CHEF) gel electrophoresis of Smal-digested genomic DNA from representative isolates identified as closely related by RFLP analysis, with the exception of the unrelated isolate S13 [5]. B. Autoradiograph of the fragments from A following transfer to nylon membranes and hybridisation with the radiolabelled pWASA DNA probe (see text). Co, community isolates: S, clinical methicillin-sensitive (MSSA) isolates: R. clinical methicillin-resistant (MRSA) isolates. No hybridisation was observed with DNA bands of lower molecular size than those shown. Molecular sizes were determined by comparison with $\lambda$ phage concatamers and ANS46 SmaI fragments [16].

Table 1. Primers used for sequencing and PCR amplification

\begin{tabular}{|c|c|}
\hline Primer ${ }^{*}$ & Nucleotide sequence \\
\hline WSA $5^{\prime}$ & 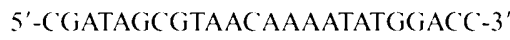 \\
\hline WSA 3' & $5^{\prime}-C^{\prime}$ (iACiTC 'TC C TTTTACAGGTC CATA-3' \\
\hline WSA 2 & 5'-GC('GTCGTTATTGTCTTCTCACCT-3' \\
\hline WSA $2 R$ & 5'-AGGTGAGAACiACAATAAC CAACGC -3' \\
\hline WSA 3 & $5^{\prime}$-CTGGAACTTC 'TC TTTCTCTCCTG-3' \\
\hline
\end{tabular}

sprimers WSA 5' and WSA 3' were designed from the 40-bp Taq fragment (WASA), whereas WSA 2 and WSA 3 were designed from genomic sequence information obtained with WSA $3^{\prime}$ (see Results). WSA $2 R$ is the reverse sequence of WSA 2, which was designed for use in PC R amplification to screen for recombinant clones (see Haterials and methods).

(IBI). Two ORFs were identified: ORF 1 of $2475 \mathrm{bp}$, encoding 824 amino acids, starting with the initiation codon ATG at nucleotide 179 (another possible start codon was TTG at nucleotide 191), and terminating with the stop codon TGA at nucleotide 2650. A possible Shine-Dalgarno [29] sequence (ribosome binding site, RBS) was found 14 nucleotides upstream from the ATG start codon, and several potential -35 and -10 promoter sequences were also identified (data not shown). Although there was another ATG start codon at nucleotide 41 , it is unlikely that it is utilised because there is no potential RBS upstream from this position.

ORF2 of $576 \mathrm{bp}$, encoding 192 amino acids, was identified in the third translational frame, starting with a GTG initiation codon at nucleotide 2880 and terminating with a TAG codon at position 3456 . RBS and promoter sequences were identified at $c$.
$60 \mathrm{bp}(-35$ and -10$)$ upstream from the GTG start codon. It is noteworthy that the sequence homology and the position of the promoter sequences with respect to this putative initiation codon do not conform with consensus sequences from other bacteria (data not shown). Although GTG is not a commonly used initiation codon, it has been reported to have this function in the synthesis of several bacterial proteins [30]. Codon usage analysis revealed a preference for $\mathrm{A}: \mathrm{T}$ bases at the third position of the codons with only $21 \% \mathrm{G}: \mathrm{C}$, which is similar to other structural genes of $S$. aureus [31].

\section{Repeating unit region of ORFI}

Beginning at nucleotide 265 of the sequence of ORF1, there are six tandem repeats that make up c. $66 \%$ of the sequence. Each repeating unit consists of 384 nucleotides, encoding 128 amino acids, and the entire repeat region encodes 768 amino acids (Fig. 5). The six repeats are similar, differing only in 16-19 nucleotides of the 384 bases; most of the variations occur at the same nucleotide positions within each repeat unit (Fig. 5). Of the nucleotide variations, nine resulted in eight amino-acid differences between the peptide sequences of the repeats, whereas the remaining variations were silent nucleotide substitutions.

\section{Analysis of the deduced amino-acid sequence for $O R F I$ and $O R F 2$}

A hydropathy profile of the deduced amino-acid sequence from both ORFs shows a pronounced hydrophilic character for the predicted polypeptides 


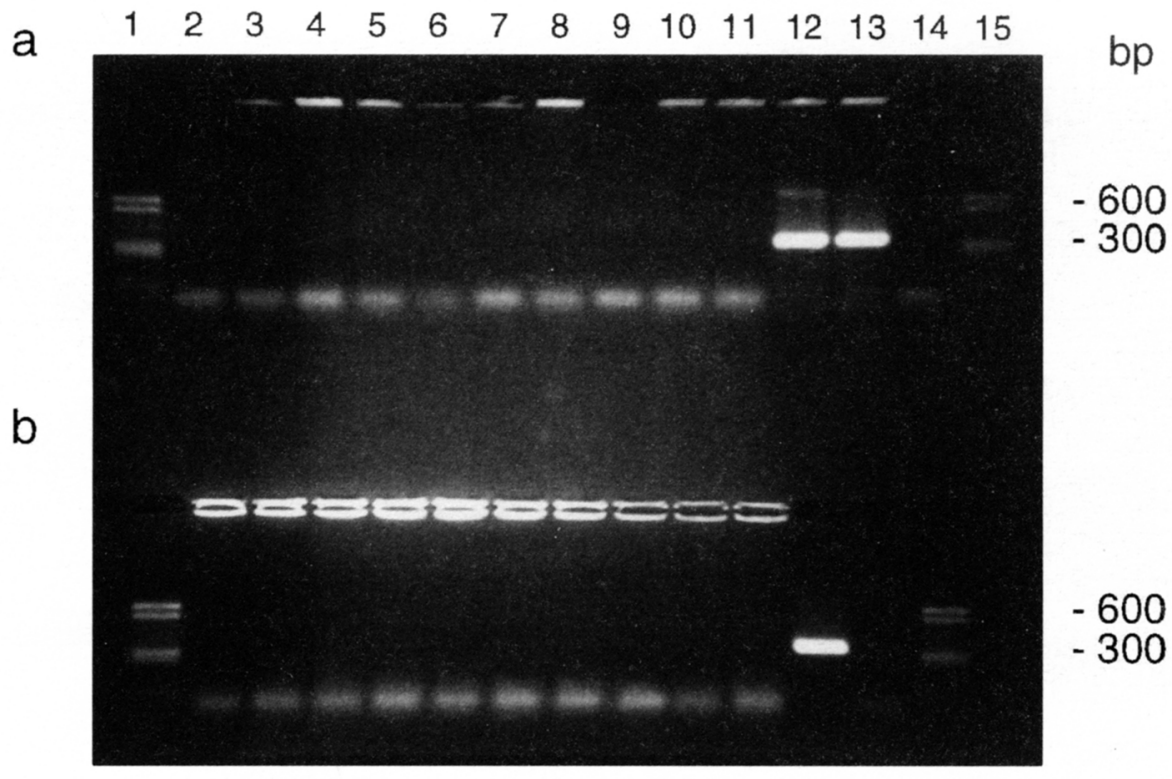

$\begin{array}{llllllllllllll}1 & 2 & 3 & 4 & 5 & 6 & 7 & 8 & 9 & 10 & 11 & 12 & 13 & 14\end{array}$

Fig. 4. Agarose gel electrophoresis of $P C R$ amplification products generated with primers WSA $3^{\prime}$ and WSA $2 R$ from recombinant plasmid clones containing ISP8-specific DNA (see text). A. PCR amplification products from pooled recombinant clones (each lanes represents a pool of 10 recombinant clones): lane 12. PCR product obtained from a pool of recombinants with specific DNA from strain ISP8: 13. PCR product from the genomic DNA of ISP8: 14. negative control with no DNA added to the PCR reaction: 1 and $\mathbf{1 5}$. molecular size markers. B. PCR amplification products from each recombinant clone pooled in lane 12 shown in $\mathbf{A}$. Lane 12 of $\mathbf{B}$ contains the recombinant plasmid clone with ISP8-specific DNA (pDSA): 13, negative control; 1 and 14, molecular size markers. Faint bands of $($. $600 \mathrm{bp}$ are a result of primers annealing at repeat sequences within DSA (see text). Low molecular size bands are unused primers.

$100 \mathrm{bp}$

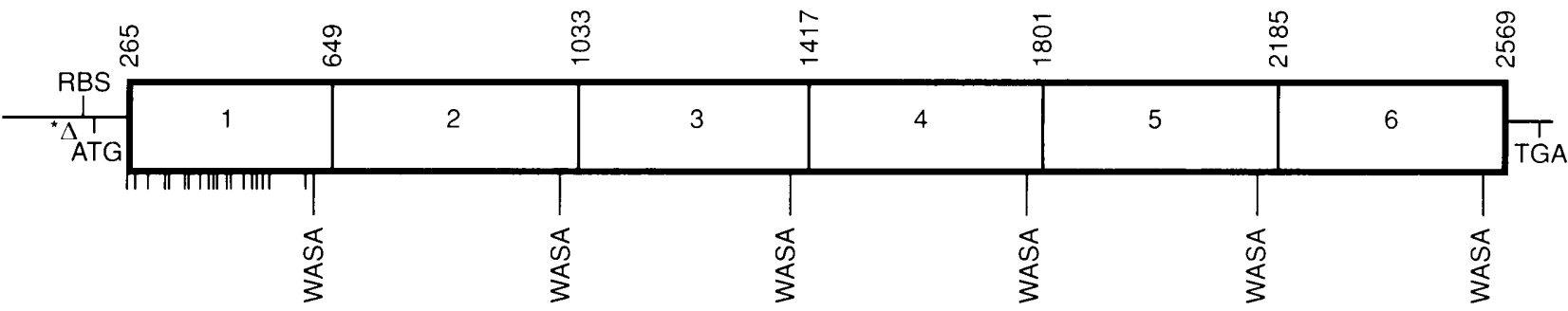

Fig. 5. Schematic representation of ORF1. The structure of the repeated units based on nucleotide sequence analysis is summarised. The initiation and termination codons for ORF1 are at nucleotide positions 179 and 2650 . respectively (see text). The numbers above the boxes indicate the first nucleotide of each repeat unit within ORFI. The numbers within the boxes indicate the numbers of the repeated units. WASA designates the position of the 40-bp Taql fragment within each repeat. Potential -35 and -10 promoter sequences are indicated with $*$ and $\Delta$, respectively; RBS, ribosome binding site. The relative sites of nucleotide substitutions within the repeated units are shown (|) for the first repeated unit.

(Fig. 6) [32-34]. Also shown are the surface probability, antigenic index and secondary structure generated with the MacVector 3.5 software. The features revealed are characteristic for surface proteins from gram-positive bacteria. The deduced amino-acid sequence for ORF1 and ORF2 predicts pI values of 4.83 and 8.75 , respectively, and calculated mol. wts of 90783 Da and $21038 \mathrm{Da}$, respectively. Both predicted protein products are rich in lysine and proline, with each making up about $13 \%$ of the total amino acids in the translated products.

A BLAST search for similarities identified limited amino-acid sequence similarities of ORFl with the surface-associated $C$ protein $\alpha$ antigen of group $B$ streptococci, collagen $\ell$ type proteins and neurofilament triplet proteins from man and mouse. It is noteworthy that ORF1 has a similar genetic structure 

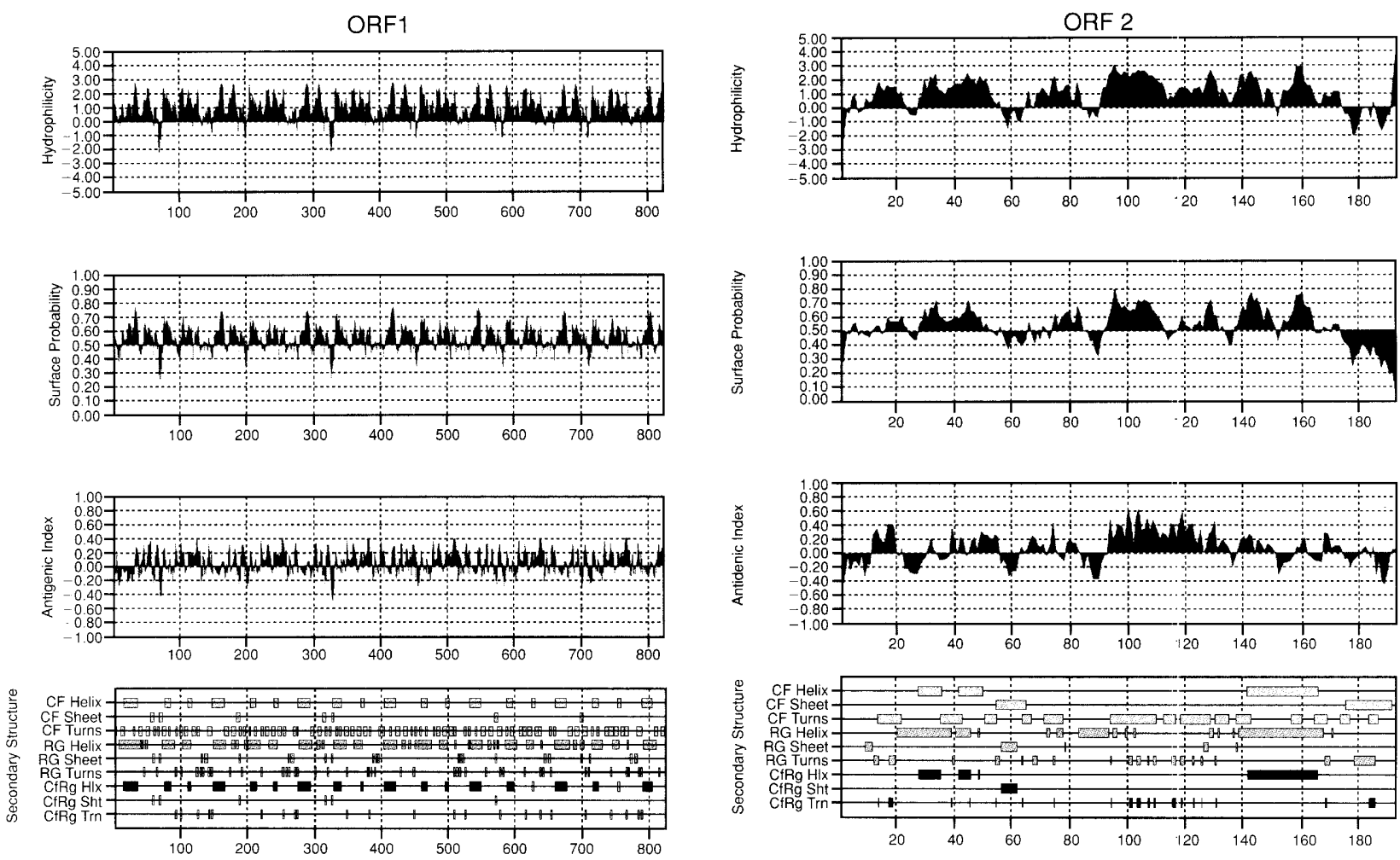

Fig. 6. Analysis of the deduced amino-acid sequence of both ORF1 and ORF2. The predicted hydrophilicity profile was determined according to Kyte and Doolittle [32] with a window of seven amino acid residues. The vertical axis indicates the relative hydrophilicity (positive values) or relative hydrophobicity (negative values). The horizontal axis denotes the amino-acid residues. Surface probability, antigenic index and secondary structure predictions were determined with the Mac Vector 3.5 (IBI) computer software, which utilises a combination of algorithms. Values $>0.5$ (surface probability) indicate amino acids exposed to the surface; values $>0.0$ (antigenic index) indicate surface peaks that might be antigenic sites. CF, Chou-Fasman method [33]; RG, Robson-Garnier method [34]; CfRg, a method for secondary structure prediction combining the latter two; Hlx, helix; Sht, sheet; Trn, turn.

to the $\mathrm{C} \alpha$ antigen gene, which contains nine identical 246 nucleotide tandem repeating units. The shared similarities between the $\mathrm{C} \alpha$ antigen protein and ORF1 encompassed the repeated region, with $26 \%$ of amino acids identical and $18 \%$ conservative substitutions over a region of 642 amino acids (Fig. 7).

Similarly, ORF2 amino-acid sequence analysis showed limited homologies to proline-rich proteins such as sporozoite surface protein 2 from Plasmodium yoelii, neurofilament triplet $M$ protein from chicken, and a glutamic acid-specific endopeptidase from $S$. aureus (data not shown).

\section{Discussion}

The observed clonality of MRSA populations that dominate Australian hospitals [5, 17, 19] suggests that clonal, clinical isolates are equipped specifically with some factor(s) that operate within the hospital environment, leading to selection of the clonal population. Studies by Le Clerc and coworkers [35] have revealed that certain subsets of E. coli and Salmonella have a higher than normal mutation rate, and these subsets are common among the pathogenic strains of these bacteria [35]. This suggests that such subsets might be better equipped to adapt in a challenging environment.

This study aimed to begin an identification, at the genetic level, of factors associated specifically with clonal populations of $S$. aureus. The search for differences between clonal, clinical isolates and community isolates was based on the assumption that the former are equipped with specific genes or DNA that is associated preferentially with the virulent lineages. Examination of pathogenic bacterial populations has shown that virulence is not associated randomly with clones $[36,37]$. Particular clones appear to be more important than members of the population at large. For example, Musser et al. [3] showed that a single clone of $S$. aureus was responsible for most cases of toxic shock syndrome in worldwide collections of $S$. aureus producing the toxin TSST-1. Accordingly, using the strategy of subtractive hybridisation, a $3.5-\mathrm{kb}$ Dra I DNA fragment (DSA) was identified, cloned and sequenced from the clinically isolated ISP8 strain. Hybridisation analysis revealed this DNA fragment to be present in the genomes of all MRSA isolates tested. It was also present, at lower frequency (c. 30\%) in the genomes 


\begin{tabular}{|c|c|c|c|}
\hline \multirow{3}{*}{$\begin{array}{l}\mathrm{C}-\alpha \text { Ag } \\
\text { ISP8 ORF1 }\end{array}$} & 294 & TKDTV-EVTVHVTPKPV-PD-KDKYDPT--GGET-TVPQGTP-VSDKEITDLVKIP-DG- & 344 \\
\hline & 84 & TKDPINELTEY-GPETIAPGHRDEFDPKLPTGEKEEVP-GKPGIKNPETGDVVRPPVDSV & 141 \\
\hline & & 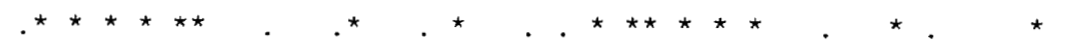 & \\
\hline $\mathrm{C}-\alpha \mathrm{Ag}$ & 345 & SK-GVPTVVGDR-PDT-NVP-G-DHKVTVEVTYPDGT-KDTVEVTVHVTPKPVPDKD-KY & 397 \\
\hline \multirow[t]{2}{*}{ ISP8 ORF1 } & 142 & TKYG-P-VKGDSIVEKEEIPFEKERKFNPDLA-P-GTEKVTRE-G-QKGEKTITTPTLK- & 194 \\
\hline & & 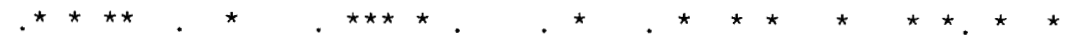 & \\
\hline $\mathrm{C}-\alpha \mathrm{Ag}$ & 398 & DP-TGGETTVPQGTPVSDKEIT-DLVK-IPD-GSKGVPTVVGDR-P-DTNVP-GDHKVIV & 450 \\
\hline \multirow[t]{2}{*}{ ISP8 PRF1 } & 195 & NPLT-GE-IISKGES-KE-EITKDPINELTEYGPETI-T-PGHRDEFDPKLPTGE-KEEV & 247 \\
\hline & & 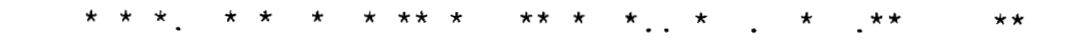 & \\
\hline $\mathrm{C}-\alpha \mathrm{Ag}$ & 451 & EVTYYPDGTKDTVEVTVHVT-PKPVPDK-DKYDPTGGETTVP-QGTPVSDKE--IT-DLVK & 504 \\
\hline \multirow[t]{2}{*}{ ISP8 ORF1 } & 248 & PGK-P-GIKNP-E-TGDVVRP-PV-DSVTKYGPVKGDSIVEKEEIP-FEKERKFNPDLA- & 299 \\
\hline & & 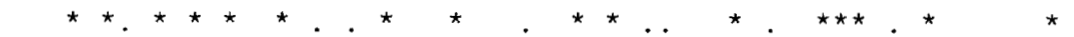 & \\
\hline $\mathrm{C}-\alpha$ Ag & 505 & IPDGS-KGVPTVVGDRPD-T-NVPG-DHKVT-VEVT-Y-P-DG-TKDTV-EVTVVVTPKP & 554 \\
\hline \multirow[t]{2}{*}{ ISP8 ORF1 } & 300 & -P-GTEK-V-TREGQKGEKTITTPTLKNPLTGVIISKAEPKEEITKDPINELPEY-GPET & 354 \\
\hline & & 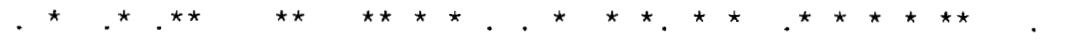 & \\
\hline $\mathrm{C}-\alpha \mathrm{Ag}$ & 555 & V-PD-KDKYDPT--GGET-TVPQGTP-VSDKEITDLVKIP-DG-SK-GVPTVVGDR-PDT & 604 \\
\hline \multirow[t]{2}{*}{ ISP8 ORF1 } & 355 & ITPGHRDEFDPKLPTGEKEEVP-GKPGIKNPETGDVVRPPVDSVTKYG-P-VKGDSIVEK & 411 \\
\hline & & 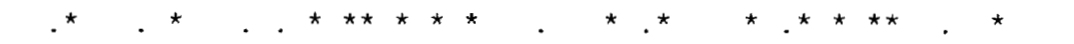 & \\
\hline $\mathrm{C}-\alpha \mathrm{Ag}$ & 605 & -NVP--GDHKVTVEVTYPDGT-KDTVEVTVHVTPKPVPDKD-KYDP-TGGETTVPQGTPV & 658 \\
\hline \multirow[t]{2}{*}{ ISP8 ORF1 } & 412 & EEIPFKKERKFNPDLA-P-GTEKVTRE-G-QKGEKTIPTPTLK-NPLT-GE-IISKGES- & 463 \\
\hline & & 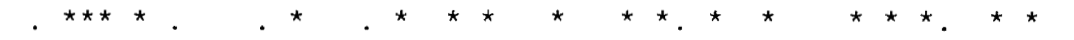 & \\
\hline $\mathrm{C}-\alpha \mathrm{Ag}$ & 659 & SDKEIT-DLVK-IPD-GSKGVPTVVGDR-P-DTNVP-GDHKVIVEVTYYPDGTKDIVEVTV & 712 \\
\hline \multirow[t]{2}{*}{ ISP8 ORF1 } & 464 & KE-EITKDPINELTEYGPETI-T-PGHRDEFDPKLPTGE-KEEVPGK-P-GIKNP-E-TG & 515 \\
\hline & & 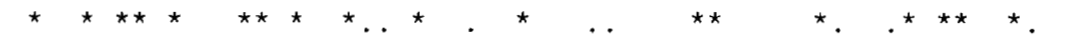 & \\
\hline $\mathrm{C}-\alpha \mathrm{Ag}$ & 713 & HVT-PKPVPDK-DKYDPTGGETTVP-QGTPV-SDKEIT-DLV----KI-PDGSKGVPTVV & 762 \\
\hline \multirow[t]{2}{*}{ ISP8 ORF1 } & 516 & DVVRP-PV-DSVTKYGPVKGDSIVEKEEIPFKKERKFNPDLAPGTEKV'TREGQKGEKTIT & 573 \\
\hline & & 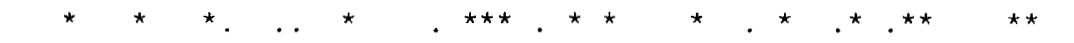 & \\
\hline $\mathrm{C}-\alpha \mathrm{Ag}$ & 763 & GDRPD-TN-VPGDHKVT-VEVTYPDGTKDTV-EVIVHVTPKPV-PD-KDKXDPT--GGET & 814 \\
\hline ISP8 ORF1 & 574 & -T-PTLKNPLTGE-IISKGESK-EEITKDPINELTEY-GPETITPGHRDEFDPKLPTGEK & 628 \\
\hline & & 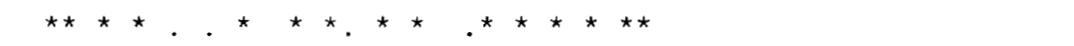 & \\
\hline $\mathrm{C}-\alpha \mathrm{Ag}$ & 815 & -TVPQGTP-VSDKEITDLVKIP-DG-SK-GVPTVVGD 846 & \\
\hline ISP8 ORF1 & 629 & EEVP-GKPGIKNPETGDVVRPPVDSVTKYG-P-VKGD 662 & \\
\hline
\end{tabular}

Fig. 7. Comparison and alignment of the deduced amino-acid sequence from ORF1 (ISP8 ORF1) with the amino-acid sequence of the $\mathrm{C} \alpha$ antigen ( $\mathrm{C} \alpha \mathrm{Ag}$ ) from group $\mathrm{B}$ streptococci. Identical amino-acid residues are indicated by $*$ and conservative substitutions are indicated by

of a few closely related antibiotic-susceptible clinical isolates. It was also present in a small minority $(10 \%)$ of community isolates. Therefore, the presence of this sequence correlates with the clonal population, which includes the MRSA and the few closely related MSSA and community isolates.

Although only $84 \%$ of the clinical isolates and $10 \%$ of the community isolates carried this specific DNA sequence, the former isolates represent dominant types of MRSA isolated from hospital infections in eastern Australia during the period 1982-1993 [5, 17, 19]. These isolates were closely related to the standard strain ISP8 isolated originally in the UK during the 1950s from a clinical environment [12]; i.e., they appear to have a common clonal background. The MSSA isolates were not involved in outbreaks and, with the exception of strains S5 and S6 (Fig. 3), were not related closely to each other or to the other clonal group [5]. There is no evidence to indicate that these MSSAs were involved in severe infections, colonisation or spread within the hospital environment.

The fact that closely related MRSA and MSSA types coexist in the clinical environment [28] suggests that certain types of selection, other than those exerted by antibiotic usage, select for the successful type(s) in the clinical environment. DSA may occur more frequently in the clinical clonal population because it encodes functions that are related directly to virulence, or is linked genetically with other genes related to virulence [38-41]. In any case, such sequences may prove valuable in the epidemiological tracking and early identification of clinically significant isolates of $S$. aureus.

Analysis of the ORF1 sequence in DSA revealed 
genetic structural properties shared by a number of gram-positive genes coding for cell surface proteins that are thought to be involved in the pathology of these bacteria [42]. Genes encoding protein A, collagen adhesin and fibronectin-binding protein of $S$. aureus, and $\mathrm{M}$ proteins of group A streptococci, IgG binding proteins from both group $A$ and $G$ streptococci, and the $\mathrm{C}$ protein $\alpha$ antigen of group $\mathrm{B}$ streptococci have been reported to consist of tandemly repeated regions that are highly homologous (within a gene) and are thought to be a result of a series of stepwise gene duplication events [42-45]. It is possible that the nucleotide repeats in these genes are important for generating genotypic and phenotypic variability by acting as sites for gene re-arrangements leading to deletion or duplication events, resulting in evolved antigenic diversification. Also, it is possible that duplication of DNA is a mechanism to amplify point mutations within a repeat, which again would create antigenic diversity [42].

Although a search for possible amino-acid signal sequences was carried out, none was identified. This is similar to the situation reported with a $S$. aureus peptidoglycan hydrolase (amidase) gene, lytA, which has been reported to lack a signal sequence [46]. Whether the failure to identify signal sequences for ORF1 and ORF2, is a result of sequence divergence or the loss of the sequences requires analysis. Interestingly, a tetrapeptide (LPTG), similar to the pentapeptide consensus LPXTG which has been found to be conserved among other gram-positive surface proteins and is thought to mediate the binding of surface proteins to the cell wall [47], appears throughout ORF1. A similar sequence, LPKTG, was identified in ORF2 at the C-terminal end of this amino-acid sequence, which might likewise be important for cell wall anchoring [47]. Further analyses are in progress to identify these proteins, their properties and the mechanisms involved in their synthesis and secretion, and to examine their importance in the pathogenesis of $S$. aureus infections.

We thank Dr P. R. Matthews for his valuable comments, G. Sargent for her technical assistance and D. Mann for his advice. This investigation is the subject of international patent application number: PCT/AU96/00353

\section{References}

1. Finlay BB, Falkow S. Common themes in microbial pathogenicity. Microbiol Rev 1989; 53: 210-230.

2. Musser JM, Selander RK. Genetic analysis of natural populations of Staphylococcus aureus. In: Novick RP (ed) The molecular biology of the staphylococci. New York, VCH. 1990: $59-67$.

3. Musser JM, Schlievert PM, Chow AW et al. A single clone of Staphylococcus aureus causes the majority of cases of toxic shock syndrome. Proc Natl Acad Sci USA 1990; 87: 225-229.

4. Achtman M, Hakenbeck R. Recent developments regarding the evolution of pathogenic bacteria. In: Hormaeche CE. Penn CW, Smyth CJ (eds) Molecular biology of bacterial infection: current status and future perspectives. Society for General
Micobiology Symposium no. 49. Cambridge: Cambridge University Press. 1992: 13-31.

5. El-Adhami W, Stewart PR. Genome organisation of Staphylococcus aureus isolates from different populations. $J$ Med Microbiol 1997: 46: 297-306.

6. Lamar EE, Palmer E. Y-encoded, species-specific DNA in mice: evidence that the $\mathrm{Y}$ chromosome exists in two polymorphic forms in inbred strains. Cell 1984; 37: 171-177.

7. Kunkel LM, Monaco AP, Middlesworth W, Ochs HD, Latt SA Specific cloning of DNA fragments absent from the DNA of a male patient with an $\mathrm{X}$ chromosome deletion. Proc Natl Acad Sci USA 1985; 82: 4778-4782.

8. Matthews PR, Reed KC, Stewart PR. The cloning of chromosomal DNA associated with methicillin and other resistances in Staphylococcus anreus. J Gen Microbiol 1987; 133: $1919-1929$.

9. Nussbaum RL, Lesko JG, Lewis RA, Ledbetter SA, Ledbetter DH. Isolation of anonymous DNA sequences from within a submicroscopic $X$ chromosomal deletion in a patient with choroidermia, deafness, and mental retardation. Proc Natl Acad Sci USA 1987: 84: 6521-6525.

10. Lisitsyn N. Lisitsyn N, Wigler M. Cloning the differences between two complex genomes. Science 1993; 259: 946-951.

11. Patel AH, Foster TJ, Pattee PA. Physical and genetic mapping of the protein A gene in the chromosome of Staphylococcus aureus 8325-4. J Gen Microbiol 1989; 135: 1799-1807.

12. Novick RP, Roth C. Plasmid-linked resistance to inorganic salts in Staphylococcus aureus. J Bacteriol 1968: 95: 1335-1342.

13. Heieine N, Stewart PR. Physiological determination of methicillin resistance in Staphrlococcus aureus: comparison of clinical and genetically derived isolates. $J$ Antimicroh Chemother 1986: 17: 705-715.

14. Gillespie M, Lyon B, Loo L, Matthews P, Stewart P, Skurray R. Homologous direct repeat sequences associated with mercury, methicillin, tetracycline and trimethoprim resistance determinants in Staphylococcus aureus. FEMS Microbiol Lett 1987; 43: $165-171$.

15. Skinner S, Inglis B, Matthews PR, Stewart PR. Mercury and tetracycline resistance genes and flanking repeats associated with methicillin resistance on the chromosome of Staphylococcus aureus. Mol Microbiol 1988; 2: 289-292.

16. Inglis B. Matthews PR, Stewart PR. Induced deletions within a cluster of resistance genes in the mec region of the chromosome of Staphylococcus aureus. J Gen Microbiol 1990; 136 2231-2239.

17. El-Adhami W, Roberts L, Vickery A, Inglis B, Gibbs A, Stewart PR. Epidemiological analysis of a methicillin-resistant Staphylococcus aureus outbreak using restriction fragment length polymorphisms of genomic DNA. J Gen Microbiol 1991; 137: 2713-2720.

18. Dubin DT, Chikramane SG, Inglis B, Matthews PR, Stewart PR. Physical mapping of the mec region of an Australian methicillin-resistant Staphylococcus aureus lineage and a closely related American strain. $J$ Gen Microbiol 1992; 138: 169-180.

19. Stewart PR, El-Adhami W, Inglis B, Franklin JC. Analysis of an outbreak of variably methicillin-resistant Staphylococcus aureus with chromosomal RFLPs and mec region probes. $J$ Med Microbiol 1993; 38: 270-277.

20. Lyon BR, Iuorio JL, May JW, Skurray RA. Molecular epidemiology of multi-resistant Staphylococcus atreus in Australian hospitals. J Med Microbiol 1984; 17: 79-89.

21. Stewart PR, El-Adhami W, Inglis B. Pulsed-field gel electrophoresis: applications to bacteria. In: Dale JW, Sanders PG (eds) Methods in gene technology, vol 2. Greenwich, CT, JAI Press Inc. 1994: 178-205.

22. Sambrook J, Fritsch EF, Maniatis T. Molecular cloning: a laboratory manual, 2nd edn. Cold Spring Harbor, NY, Cold Spring Harbor Laboratory Press. 1989.

23. Pattee PA. The genetic map of Staphylococcus aureus. In Sonenshein AL, Hoch JA, Losick R (eds) Bacillus subtilis and other gram-positive bacteria: biochemistry, physiology, and molecular genetics. Washington, DC, American Society for Microbiology. 1993: 489-496.

24. Pattee PA. Genetic and physical mapping of the chromosome of Staphylococcus aureus NCTC 8325. In: Drlica K, Riley M (eds) The bacterial chromosome. Washington, DC, American Society for Microbiology. 1990: 163-169.

25. Reed KC. Nucleic acid hybridizations with positive charge- 
modified nylon membrane. In: Dale JW. Saunders PG (eds) Methods in gene technology, vol 1. Greenwich. CT. JAI Press Inc. 1991: 127-160.

26. Feinberg AP, Vogelstein B. A technique for radiolabeling DNA restriction endonuclease fragments to high specific activity. Anal Biochem 1983: 132: 6-13.

27. Feinberg AP, Vogelstein B. Addendum: A technique for radiolabeling DNA restriction endonuclease fragments to high specific activity.' Anal Biochem 1984; 137: 266-267.

28. Inglis B, El-Adhami W, Stewart PR. Methicillin-sensitive and -resistant homologues of Staphlococ'us aureus occur together among clinical isolates. J Infect Dis 1993: 167: 323-328.

29. Shine J. Dalgarno L. The $3^{\prime}$-terminal sequence of Escherichia coli $16 \mathrm{~S}$ ribosomal RNA: complementarity to nonsense triplets and ribosomal binding sites. Proc Natl Acad Sci USA 1974: 71: $1342-1346$.

30. Signäs C. Raucci G, Jönsson K et al. Nucleotide sequence of the gene for a fibronectin-binding protein from Staphlococcus aureus: use of this peptide sequence in the synthesis of biologically active peptide. Proc Natl Acad Sci USA 1989; 86: 699-703.

31. Wada K, Aota S, Tsuchiya R, Ishibashi G, Gojobori T, Ikemura $\mathrm{T}$. Codon usage tabulated from the GenBank genetic sequence data. Nucleic Acids Res 1990; 18 Suppl: 2367-2411.

32. Kyte J, Doolittle RF. A simple method for displaying the hydropathic character of a protein. $J$ Mol Biol 1982; 157: $105-132$.

33. Chou PY, Fasman GD. Prediction of the secondary structure of proteins from their amino acid sequence. Adv Enzrmol Relat Areas Mol Biol 1978; 47: 45-148

34. Garnier J, Osguthorpe DJ, Robson B. Analysis of the accuracy and implications of simple methods for predicting the secondary structure of globular proteins. $J \mathrm{Mol} \mathrm{Biol} \mathrm{1978;}$ 120: $97-120$.

35. LeClerc JE, Li B, Payne WL, Cebula TA. High mutation frequencies among Escherichia coli and Salmonella pathogens. Science 1996; 274: 1208-1211.

36. Selander RK, Musser JM, Caugant DA, Gilmour MN, Whittam
TS. Population genetics of pathogenic bacteria. Microb Pathog 1987; 3: 1-7.

37. Selander RK. Musser JM. Population genetics of bacterial pathogenesis. In: Iglewski BH, Clark VL (eds) The bacteria: a treatise on structure and function: molecular basis of bacterial pathogenesis, vol X1. San Diego, CA. Academic Press 1990: $11-36$.

38. Hartl DI, Dykhuizen DE. The population genetics of Escherichia coli. Annu Rev Genet 1984; 18: 31-68.

39. Milkman R, Stoltzfus A. Molecular evolution of the Escherichia coli chromosome. II. Clonal segments. Genetics 1988; 120: $359-366$.

40. Milkman R, Bridges MM. Molecular evolution of the Escherichia coli chromosome. III. Clonal frames. Genetics 1990; 126: 505-517.

41. Guttman DS, Dykhuizen DE. Detecting selective sweeps in naturally occurring Escherichia coli. Genetics 1994; 138: 993-1003.

42. Michel JL, Madoff LC, Olson K, Kling DE, Kasper DL. Ausubel FM. Large, identical, tandem repeating units in the $C$ protein alpha antigen gene, $b c a$, of group B streptococci. Proc Natl Acad Sci USA 1992; 89: 10060-10064.

43. Uhlén $M$, Guss B, Nilsson B, Gatenbeck S, Philipson L, Lindberg $M$. Complete sequence of the staphylococcal gene encoding protein A. A gene evolved through multiple duplications. J Biol Chem 1984; 259: 1695-1702.

44. Wren BW. A family of clostridial and streptococcal ligandbinding proteins with conserved $\mathrm{C}$-terminal repeat sequences Mol Microbiol 1991; 5: 797-803.

45. Patti JM, Jonsson H, Guss B et al. Molecular characterization and expression of a gene encoding a Staphlococcus aureus collagen adhesin. $J$ Biol Chem 1992; 267: 4766-4772.

46. Wang X, Wilkinson BJ, Jayaswal RK. Sequence analysis of a Staphlococcus aureus gene encoding a peptidoglycan hydrolase activity. Gene 1991; 102: 105-109.

47. Schneewind O. Fowler A, Faull KF. Structure of the cell wall anchor of surface proteins in Staphlococcus atreus. Science 1995; 268: $103-106$ 